\title{
Routinemäßige Anwendung der PCR bei der Untersuchung von Lebensmitteln auf Salmonellen
}

\author{
Dr. R. Stark, Dr. D. Mäde, Dr. S. Kahle und Dr. A. Wicke \\ Landesamt für Verbraucherschutz Sachsen-Anhalt, Freiimfelder Str. 66/68, 06112 Halle
}

\section{Zusammenfassung/Erläuterung}

Salmonellen gehören zu den häufigsten Krankheitserregern. Die herkömmliche mikrobiologische Untersuchungsmethode erfordert einen hohen Arbeits- und Zeitaufwand. Mit der Anwendung einer Kombination von mikrobiologischer und molekularbiologischer Methodik kann dieser Aufwand reduziert werden.

Die Anforderungen an die Einführung der PCR zum Nachweis von Salmonellen waren, dass im Vergleich zur kulturellen Methode keine falsch negativen Ergebnisse auftreten dürfen und dass die Methodik effektiv und kostengünstig ist.

Drei molekularbiologische Nachweissysteme wurden geprüft: (a) PCR nach Rahn et al. (1992) mit Agarosegeldetektion (Verifizierung durch DIG-markierte Oligonukleotidsonde), (b) Real Time PCR mit einer TaqMan-Sonde nach Reiting (2003) und (c) ein kommerziell erhältliches System mit TaqMan-Sonde und interner Positivkontrolle (Sure Food Salmonella, Congen). Diese Systeme entsprechen der Methode L 00.00-52 der Amtlichen Sammlung und verwenden die dort im Anhang festgelegten PCR-Primer. In allen Systemen wird mittels einer Amplifikationskontrolle auf Inhibition der PCR geprüft.

Die in-house-Validierung bestand aus drei Teilen:

- In einem Sensitivitätstest wurde sowohl die DNA-Extraktion aus der Voranreicherung als auch aus der Selektivanreicherung geprüft. Es zeigte sich, dass eine zweistufige Anreicherung erforderlich ist, um bei niedriger Zahl von Salmonellen und hoher bakterieller Hintergrundflora die erforderliche Sensitivität zu gewährleisten. Die DNA-Extraktion kann sowohl über auf Silicasäulen basierenden und automatisierbaren Extraktionskits als auch mittels der kostengünstigen thermischen Lyse erfolgen. Die Ergebnisse beider Extraktionsmethoden hinsichtlich Koextraktion von inhibitorischen Substanzen und Sensitivität der PCR sind bei zweistufiger Anreicherung gleich. Für die Routineuntersuchung wurde die thermische Lyse ausgewählt.

- Nachweis der Bestimmungsgrenze durch Inokulationsversuche in zwei Lebensmittelmatrices (Hackfleisch und Feinbackware). Die Bestimmungsgrenze wurde durch Anwen- dung des MPN- Verfahrens ermittelt. Es waren keine Unterschiede der Bestimmungsgrenze der molekularbiologischen Methode mit dem vergleichend durchgeführten kulturellen Verfahren feststellbar.

- Parallele Anwendung der kulturellen und molekularbiologischen Methode über den Zeitraum von sieben Monaten. Bei der Paralleluntersuchung von 1978 Routineproben sowohl mit den molekularbiologischen Verfahren als auch mit der herkömmlichen kulturellen Methode traten keine falsch negativen Ergebnisse in der PCR auf. Jedoch ließen sich nicht alle PCR-positiven Proben kulturell bestätigen. Die falschpositiv-Rate von $0,73 \%$ wird jedoch als gut angesehen.

Seit Februar 2003 wird die Real Time PCR in Verbindung mit einer zweistufigen Anreicherung in der Routineuntersuchung als alleiniges Verfahren zum Nachweis von Salmonellen angewandt. Molekularbiologisch positive Proben gelten als Salmonella-verdächtig. In diesen Fällen schließt sich eine Erregerisolierung an. Für die lebensmittelrechtliche Beurteilung wird das kulturelle Ergebnis herangezogen.

Durch die parallele Validierung von drei Verfahren ist die molekularbiologische Salmonella-Analytik unabhängig von einzelnen Herstellern wie auch von dem Real-time PCR-Gerät.

Der Vorteil der PCR besteht in (a) der verkürzten Untersuchungszeit bis zum Vorliegen erster Ergebnisses (negativ oder verdächtig nach 27 Stunden gegenüber mindestens 68 Stunden), (b) dem Nachweis der Pathogenitätsfaktoren der Salmonellen, wodurch eine lebensmittelhygienische Relevanz der nachgewiesenen Erreger gegeben ist und in (c) dem verringerten Aufwand für mikrobiologische Arbeiten (Beimpfen und Bewerten der Selektivnährmedien, Medien für biochemische Prüfungen, Antisalmonella-Seren).

Als Nachteil sind die erforderliche Umstellung der Labororganisation sowie die gegebenenfalls entsprechend des durchgeführten Verfahrens anfallenden höheren Kosten anzusehen.

\section{Beschluss}

Kenntnisnahme 